\title{
A VELHICE PESSOAL NO IMAGINÁRIO DE ESTUDANTES DE ENFERMAGEM
}

\section{Resumo}

Marinês Tambara Leite*

Para este novo contexto que se apresenta, em face das transformações e demandas sociais que emergem a partir do aumento vertiginoso da população idosa, há a necessidade da formação de recursos humanos, adequadamente qualificados, nas diversas áreas do conhecimento, a fim de dar conta das necessidades oriundas deste estrato populacional. Com o objetivo de identificar as expectativas que os estudantes de enfermagem possuem sobre sua velhice, realizou-se um estudo descritivo, do tipo exploratório. Participaram 32 acadêmicos, sendo que a coleta dos dados ocorreu por meio de um instrumento em que os alunos foram convidados a redigir livremente acerca do tema "como imagino minha velhice". Para a análise das informações, os preceitos da análise de conteúdo foram adotados. Emergiram expectativas positivas em relação à velhice, como ter situação financeira estável, poder manter os vínculos familiares, compartilhar ativamente o espaço doméstico, ser uma pessoa saudável, permanecer independente e com autonomia, podendo usufruir a condição de ser idoso inserido socialmente e desfrutando sua cidadania. Os estudantes imaginam vivenciar a velhice de forma plena, saudável, com boa condição econômica, sendo valorizados e, principalmente, mantendo os laços familiares.

Palavras-chave: Velhice. Enfermagem. Idoso. Envelhecimento Humano. Imaginário.

\section{Considerações Iniciais}

O crescente aumento populacional de idosos, nas últimas décadas, tem-se tornado uma questão relevante em estudos contemporâneos, nas diversas áreas do conhecimento. No âmbito da saúde e da educação, observase a ascensão dos serviços prestados a idosos e, concomitantemente, a garan-

\footnotetext{
* Enfermeira, docente do Departamento de Ciências da Saúde da Universidade Regional do Noroeste do Estado do Rio Grande do Sul - UNIJUÍ. Doutoranda do Programa de PósGraduação em Gerontologia Biomédica do Instituto de Geriatria e Gerontologia da PUC/RS. email:marinesl@unijui.tche.br
} 
tia de direitos adquiridos, como a aprovação do Estatuto do Idoso. O contexto sócio-demográfico atual é resultante das modificações que vêm ocorrendo nas taxas de mortalidade e de natalidade, aliadas ao recente desenvolvimento técnicocientífico no campo da saúde. Tais transformações têm originado demandas, bastante peculiares, no que se refere aos aspectos do cuidado, apontando para a urgente necessidade de formação e capacitação de recursos humanos no campo da saúde, dentre eles, na área de enfermagem. Esta preocupação visa qualificar as ações desenvolvidas junto às pessoas idosas e, também, dar conta das questões oriundas deste estrato populacional.

Entende-se que a prestação do cuidado a pessoas idosas envolve sentimentos, concepções e atitudes dos integrantes da equipe de enfermagem que, por meio de simbologia, dão significado e expressam como ocorre sua interação com o outro, no caso a pessoa idosa. Para Haguette (1995), os atores sociais dão sentido aos objetos, pessoas e símbolos com os quais estabelecem o seu mundo social. Nas interações sociais, os indivíduos prevêem em seu imaginário condutas antecipadas de outrem e, freqüentemente, agem em razão dessas condutas.

Menciona, ainda, que o significado de um determinado fenômeno se dá mediante a interação do eu, da mente e da sociedade, interação esta resultante da vida social, em cujo processo o indivíduo é um sujeito, um ser que interage com o outro. Nesta perspectiva, pode-se dizer que os trabalhadores de enfermagem processam o cuidado a pessoas idosas, com base na percepção que possuem acerca do envelhecimento, como ele se apresenta em sua vida pessoal e social e da interpretação que fazem do mesmo.

A interação social pode ocorrer de duas formas distintas: pela comunicação do gesto ou pelo uso de símbolos significantes (MEAD, 1977) e, ainda, ser não simbólica ou simbólica (BLUMER, 1986). Ou seja, a comunicação e a interpretação que os atores fazem de si e do outro se constitui em uma interação social.

O significado dos fenômenos e eventos resulta de conhecimentos internos das pessoas, significados estes que são produtos da vida social dos indivíduos. Em outras palavras, nenhum evento, fato ou fenômeno possui significado se não há interação dos seres humanos entre si e com seu meio, salientando que os significados dos fenômenos são, continuamente, modificados e apurados (BLUMER, 1986).

Diante do exposto e considerando que o enfermeiro é um profissional indispensável na equipe de saúde que atua junto à população idosa, é essen- 
cial que no decorrer de sua formação profissional ele seja desafiado a estudar, discutir e refletir acerca das questões relativas ao processo de envelhecimento.

Neste contexto, o objetivo deste estudo é identificar como estudantes do curso de graduação em enfermagem, visualizam sua própria velhice. Ponderase que a imagem que o estudante tem de si no futuro, reflete na maneira dele perceber, entender e interagir com pessoas idosas no ambiente de trabalho atual e, também, na forma de prestar o cuidado.

\section{Caminho Metodológico}

Uma vez que se busca apreender, a partir das manifestações verbais, as expectativas de estudantes acerca de sua velhice, tendo como fonte de informação dados de natureza subjetiva, este estudo caracteriza-se como qualitativo, exploratório, descritivo. O mesmo foi desenvolvido no Curso de Enfermagem de uma universidade situada no interior do Estado do Rio Grande do Sul. A coleta dos dados ocorreu por meio de instrumento específico, em que os estudantes foram convidados a redigir, livremente, acerca da temática: "Como imagino minha velhice".

Previamente, os alunos foram informados acerca dos propósitos da pesquisa, sendo apresentado, a cada um deles, o termo de consentimento assinado pela pesquisadora responsável, contendo os objetivos, procedimentos metodológicos, detalhamento da não necessidade de identificação nominal, garantia de anonimato e de liberdade para recusa sem implicações institucionais. Após leitura do termo de consentimento livre e esclarecido pelos estudantes, foi solicitado que assinassem o mesmo, sendo que uma via ficou em poder do aluno e outra de posse da pesquisadora. Não houve recusa por parte dos acadêmicos.

Assim, participaram 32 acadêmicos regularmente matriculados, no componente curricular Enfermagem em Gerontologia, do quinto semestre da grade curricular do Curso de Enfermagem da universidade, local de estudo. Do total de participantes, vinte e sete são do sexo feminino e cinco do sexo masculino, com idades entre 18 e 32 anos. Quanto ao estado civil, vinte e quatro são solteiros e oito casados. Todos mantêm contato com um ou mais avós, sendo que dois deles coabitam o espaço doméstico com os mesmos. 
Os preceitos da análise de conteúdo foram balizadores para a realização da análise das informações, sendo, conforme Bardin (1977), necessária a observação de três fases distintas, quais sejam: a pré-análise, a exploração do material e o tratamento dos resultados, a inferência e a interpretação.

\section{Apresentação e Interpretação dos Resultados}

Atualmente, o entendimento acerca do que seja velhice vem se modificando e, mesmo que lentamente, vem estabelecendo uma nova relação da nossa cultura com o envelhecimento. Beauvoir (1990), ao escrever acerca da velhice e seu contexto, explicita que o processo de envelhecimento vai acontecendo progressivamente com o passar dos anos, sem que as pessoas jovens percebam as modificações que ocorrem ao longo do tempo. Menciona que é o olhar do outro que vê o quanto determinado indivíduo envelheceu. Afirma que "[... ] o indivíduo idoso sente-se velho através do outro, sem ter experimentado sérias mutações; interiormente, não adere à etiqueta que se cola a ele: não sabe mais quem é" (p.358).

As mudanças que ocorrem no decorrer do processo de envelhecimento são sentidas de forma particular por cada um. A proposta da educação para o envelhecimento é modificar aquilo que está inscrito no imaginário social a respeito da velhice, colocando em ação toda energia estagnada, mal direcionada e levar o envelhescente a desenvolver o seu potencial de forma criativa, resgatando a naturalidade e a essência da vida. Atingir a idade madura significa o início de uma nova etapa da vida, que, se bem preparada e estimulada, pode ser promissora em termos de realizações de projetos, planos e sonhos que foram adiados e que se o idoso considerar o seu potencial de experiência e sabedoria acumuladas terá grandes benefícios (DUARTE, 2006).

As informações analisadas e interpretadas apontam que os estudantes participantes deste estudo possuem expectativas positivas em relação a sua própria velhice, vislumbrando possibilidades de ter uma situação financeira estável, o que lhes permitirá viver a última etapa de suas vidas tranqüila e prazerosamente. Para que isto ocorra, expõem algumas condições que devem acontecer, no decorrer da vida adulta, como ter um trabalho e constituir uma família.

Os estudantes almejam possuir estabilidade financeira, saúde e ter formado vínculos familiares para na velhice poder manter-se confortavelmente, 
aspirando, ainda, proporcionar a seus filhos segurança e melhores condições de vida do que as suas próprias.

"Ter uma vida estável e oferecer aos meus filhos o que não tive na infầncia e adolescência" (Estudante 05).

Demonstram desejo de mudança ou então de acompanhar a evolução da sociedade como um todo. Já não é mais possível simplesmente dar continuidade ao modo como seus pais viveram. As possibilidades são outras. Assim, viver a última fase da vida de modo positivo é uma questão existencial a que se propõe um número crescente de pessoas em todo o mundo, tendo em vista que o envelhecimento populacional está se generalizando (NERI, 1993). Contudo, mencionam que nem tudo deve ser modificado e que atributos como honestidade, amor e carinho são passíveis e desejáveis de serem passados para seus próprios filhos, entendendo que isto fará bem a seus descendentes.

"Que eu consiga passar aos meus filhos a mesma sinceridade, o mesmo amor, carinho que hoje meus pais estão me passando" (Estudante 11).

Possuir uma velhice saudável não é somente o resultado de um atributo individual, biológico, psicológico ou social, mas é o somatório destes e da interação entre as pessoas em mudança, que vivem numa sociedade que se encontra em constante modificação. Blumer (1986) explicita que a interação social, por sua vez, se constitui em ação coletiva, resultante do conjunto de unidades de ação (indivíduos, família, escola, igreja, sindicato, entre outros), atuando para enfrentar situações nas quais elas estão inseridas. Assim, a convivência grupal estabelece um "processo de formação, sustentação e transformação de objetos", em que os sentidos se alteram por meio da interação, modificando, conseqüentemente, o mundo das pessoas. Os sentidos são manipulados mediante um processo interpretativo, em que os indivíduos interagem consigo próprios, usando símbolos significantes.

Há, também, expectativas relacionadas à manutenção do vínculo familiar, compartilhando ativamente o espaço doméstico, sem constituir-se em um fardo para os familiares. Para isso, vislumbram ser uma pessoa velha saudável, permanecendo independente e com autonomia, podendo usufruir a condição de ser idoso inserido socialmente e desfrutando sua cidadania. 
Espero ter uma velhice saudável. Viver bem e com consciência. Olhar para trás e enxergar que fiz tudo de bom para minha vida e para a felicidade de meus filhos. Quero ter o reconhecimento dos filhos (Estudante 10).

A idéia de uma visão mais positiva do envelhecimento, que está começando a ganhar força nos dias atuais, é resultado de fatores variados, dentre os quais se destaca o crescimento numérico dos idosos no mundo inteiro. Em conseqüência, cresce entre eles a consciência dos seus direitos, assim como sua capacidade de influência nas diversas esferas sociais.

A relação com o trabalho aparece de forma enfática. O trabalho constitui-se na possibilidade de ter uma renda e, conseqüentemente, possuir condições de manterem-se economicamente. Como resultado, aspiram poder aposentar-se, recebendo remuneração suficiente para gerir seus gastos do diaa-dia e, em caso de adoecimento, pagar pelo tratamento e/ou hospitalização necessários.

Na velhice, gostaria de estar cercada pela família, praticar caminhadas e ter um bom padrão de vida, para que no caso de adoecer poder pagar um tratamento ou hospitalização (Estudante 16).

Além disso, desejam ter muito conhecimento, sabedoria e condições cognitivas para transmitir aos descendentes. Reforçam a necessidade da manutenção dos laços familiares e descartam a possibilidade de estarem abandonados ou sós. Aparece, ainda, o bom humor como atributo importante para poderem sentir-se bem e inseridos no contexto familiar e social.

Espero que eu tenha muita sabedoria e que eu possa passar meus conhecimentos adiante. Que eu possa aproveitar cada minuto da vida perto dos filhos, netos, perto das pessoas que gosto e que farão me sentir bem. Quero me sentir realizada em todos os sentidos e ser uma "velhinha" bem humorada (Estudante 21).

Estudos como o de Alencar (1998), sobre a fabricação social do idoso e o papel da educação, explicitam que é necessário preparar as gerações, independentemente da idade, para valorizar as experiências, a memória, as emoções das pessoas e a sabedoria de vida adquirida ao longo do tempo. Também, lembrar que necessidades de atenção e interação todo ser humano tem. 
Deve-se re-valorizar a pessoa idosa como um ser que continua se desenvolvendo e que é perfeitamente capaz de aprender, ensinar, criar, retomar atividades e realizar-se como pessoa, para isso não deve haver limites de qualquer natureza.

Silva (1999) contribui ao afirmar que todo ser humano é mortal e que uma grande parcela deles envelhece, raramente algum pensa sobre as questões da velhice com antecedência. Esta situação parece não fazer parte do imaginário das pessoas jovens. Desconsideram que já estão vivenciando o processo de envelhecer, pois se imaginar velho é imaginar-se uma outra pessoa. Beauvoir (1990) reforça esta questão ao mencionar que todos os jovens possuem em seu interior o velho de amanhã, porém não aceitam se reconhecer no velho que serão.

Aspectos que proporcionam bem estar, tranqüilidade, serenidade, segurança e interação entre pessoas são apontados como essenciais para uma boa velhice. Assim, almejam curtir os filhos já adultos e acompanhar o crescimento dos netos, serem felizes, valorizados e respeitados, ter amigos e, continuamente, estar na companhia de alguém.

Vale lembrar que nas colocações os alunos não consideram que poderão enfrentar empecilhos de natureza social, como dificuldades relativas ao trabalho e obstáculos decorrentes de problemas orgânicos ou psíquicos, que comumente ocorrem no decorrer do processo de envelhecimento, para atingir o que almejam em sua velhice. Talvez esta preocupação não lhes tenha ocorrido por estarem vivenciando a fase adulta jovem, etapa que usualmente estão física e psicologicamente saudáveis e, ainda, se encontram economicamente sob a custódia dos pais.

Beauvoir (1990, p. 266), ao dissertar sobre a relação do adulto com o velho, refere que a idéia perpassada é a de que o velho é um ente que "[ [... não faz mais nada [ . . . ]", que o tempo o conduz a um fim, "[ . . . ] que não é o seu fim, que não foi estabelecido por um projeto. É por isso que o velho aparece aos indivíduos ativos como uma 'espécie estranha', na qual eles não se reconhecem".

Outro aspecto, não evidenciado no discurso dos estudantes, é quanto à possibilidade de não atenderem suas aspirações em relação ao trabalho e de não atingirem a plenitude de suas expectativas no decorrer de sua vida adulta, o que poderá resultar em frustrações pessoal e profissional, refletindo na forma como viverão a última etapa da vida - a velhice. 


\title{
5 Considerações Finais
}

Os estudantes imaginam vivenciar a velhice de forma plena, tendo boa condição financeira, sendo valorizados, mantendo os laços familiares e exercendo sua cidadania. Dessa forma, pode-se inferir que os futuros enfermeiros, participantes deste estudo, estão utilizando uma simbologia positiva para seu futuro, ou seja, para sua própria velhice, o que poderá favorecer no exercício de sua prática profissional, especialmente, quando relacionada ao cuidado de pessoas idosas.

Para tanto, mantêm expectativas positivas relacionadas à última fase de sua vida, como a manutenção do vínculo familiar, residindo em seu próprio ambiente familiar e não estar na dependência de filhos e netos. Contudo, partilhando ativamente este espaço doméstico, não se constituindo em um fardo para seus familiares.

Outro desejo apontado é poder ser uma pessoa saudável, com independência e autonomia, usufruindo a condição de ser idoso inserido na sociedade, desfrutando sua cidadania. Para isso, aspiram aproveitar cada minuto da vida passeando, conversando, fazendo novas amizades.

Na velhice, almejam afastar-se do mercado de trabalho aposentandose, recebendo uma boa remuneração e tendo o tempo livre para dedicar-se e acompanhar o crescimento de seus descendentes, especialmente, dos netos. Também, poder olhar para o passado, dizer que realizaram todos os sonhos e cumpriram com os objetivos que se propuzeram no decorrer de sua existência.

Em suma, ser um indivíduo que cooperou com a sociedade na qual vive, tendo saúde, alegria, felicidade, amor, valor enquanto cidadão, com muitos amigos, sempre em companhia de alguém, preferencialmente um familiar, e com muito orgulho poder falar "eu fui uma boa pessoa e contribui para o mundo que está aí”.

\section{THE PERSONAL OLDNESS IN NURSING STUDENTS' IMAGINARY}

\begin{abstract}
In this new context, to face changes and social demands that arise from the vertiginous increase of the elderly population, it is needed a human resource foundation, qualified in different areas of knowledge, with the purpose
\end{abstract}


of handling with the necessities that come from this part of the population. We made this study with the purpose of knowing the expectation that nursing students have about their own oldness. It is a descriptive and exploratory research. Thirty two students were part of the study, and the data collection was made by instrument. The students were invited to write about the theme "how I imagine my oldness". For the information analysis, we used the content analysis precepts. It emerged positive expectations related to the oldness, like having stable money conditions, maintaining familiars bonds, sharing actively the domestic space, and being a healthy person; keeping themselves independent and with autonomy, and having the possibility of enjoying the condition of being elderly, socially included and desfructing citizenship. The students imagine themselves in the oldness, living it intensively, healthy, in a good economic condition, being appreciated and, mainly, keeping the familiar bonds.

Keywords: Oldness. Nursing. Elderly. Human Aging. Imaginary.

\section{REFERÊNCIAS}

D’ALENCAR, Raimunda Silva. A Fabricação Social do Idoso e o Papel da Educação. Revista Especiaria. Ilhéus, v. 2, p. 16-24, 1998.

BARDIN, Laurence. Análise de Conteúdo. Lisboa: Edições 70, 1977.

BEAUVOIR, Simone de. A Velhice. 3. ed. Rio de Janeiro: Nova Fronteira, 1990.

BLUMER, Herbert. Symbolic Interactionism: perspective and method. Berkeley: University of California Press, 1986.

DUARTE, Luzia Travasssos. Envelhecimento Biopsicossocial. Tiempo: el portal de la Psicogerontología, Buenos Aires, Disponível em: $<$ http:// www.psicomundo.com/tiempo/monografias/brasil.htm $>$. Acesso em: 10 jan. 2006.

HAGUETTE, Teresa Maria Frota. Metodologias Qualitativas na Sociologia. 4. ed. Petrópolis: Vozes, 1995. 
MEAD, George Herbert. On Social Psyhology. 5. ed. Chicago: University of Chicago Press, 1977.

NERI, Anita Liberalesso. Qualidade de Vida e Idade Madura. Campinas: Papirus, 1993. (Coleção Vivaidade).

SILVA, Ticyana Moralez da. A Imagem do Envelhecimento. Revista Psicologia Argumento. Curitiba, ano 17, n. 24, p. 65-72, abr. 1999. 